\title{
Combining inhaled iloprost with bosentan in patients with idiopathic pulmonary arterial hypertension
}

\author{
M.M. Hoeper*, H. Leuchte" ${ }^{\#}$, M. Halank ${ }^{\nwarrow}$, H. Wilkens ${ }^{+}$, F.J. Meyer ${ }^{\S}$, H.J. Seyfarth ${ }^{f}$, \\ R. Wensel**, F. Ripken*, H. Bremer ${ }^{\# \#}$, S. Kluge ${ }^{\tau \uparrow, ~ G . ~ H o e f f k e n ~}{ }^{\star}$ and J. Behr ${ }^{\#}$
}

ABSTRACT: Addition of inhaled iloprost to bosentan may have beneficial effects in patients with idiopathic pulmonary arterial hypertension (IPAH). A multicentre, open, randomised, controlled trial was performed to assess the safety and efficacy of inhaled iloprost in patients with IPAH who had already been treated with bosentan.

The trial was terminated early after a futility analysis predicted failure with respect to the predetermined sample size. At that time, 40 patients were randomised to receive either bosentan alone (control group) or bosentan plus inhaled iloprost (combination group) for a 12-week period.

The primary end-point, change in 6-min walking distance, was not met (mean changes $+1 \mathrm{~m}$ and $-9 \mathrm{~m}$ in the control and combination group, respectively). These results may have been skewed by three outliers in the iloprost group who presented with severe clinical worsening. None of the secondary end-points including functional class, peak oxygen uptake, and time to clinical worsening differed significantly between groups.

The current study failed to show a positive effect of adding inhaled iloprost to bosentan in idiopathic pulmonary arterial hypertension patients. Further studies involving larger sample sizes and long-term follow-up are needed to determine the efficacy of adding inhaled iloprost to bosentan in patients with idiopathic pulmonary arterial hypertension.

\section{KEYWORDS: Endothelin-receptor antagonists, prostaglandins, pulmonary hypertension}

$\mathbf{T}$ hree novel substances have recently been introduced in the treatment of pulmonary arterial hypertension (PAH) including: the endothelin receptor antagonist bosentan [1]; the phosphodiesterase-5 inhibitor sildenafil [2]; and the prostanoid iloprost, which is usually administered via inhalation [3]. Although all these substances result in clinical improvement of patients with PAH after 3-4 months of treatment, long-term results are less favourable, at least with monotherapy. A retrospective study from Germany suggested that in patients receiving first-line therapy with inhaled iloprost, survival free of transplantation or change in treatment was only $29 \%$ after 2 yrs, and $42 \%$ of patients were transitioned to i.v. prostanoid therapy [4]. A similar retrospective study from France showed that first-line therapy with bosentan resulted in an event-free survival of $44 \%$ after 2 yrs, and $45 \%$ of patients required i.v. prostanoid therapy [5]. Comparable long-term data are

For editorial comments see page 683 . not yet available for first-line therapy with sildenafil.

Several small and uncontrolled studies have provided preliminary evidence that various combinations of endothelin-receptor antagonists, phosphodiesterase- 5 inhibitors and prostanoids may be safe and efficacious in patients with $\mathrm{PAH}$ [6-9], and there is also emerging evidence to suggest that combination therapy may improve long-term outcome in this patient population [10]. However, many open questions remain as to the most effective combination regimens and the ideal timing of combination therapy, since longterm randomised, controlled clinical trials have not yet addressed these issues [11]

The present study describes the results of the Combination Therapy of Bosentan and aerosolised Iloprost in Idiopathic Pulmonary Arterial Hypertension (COMBI) trial, a German multicentre study addressing the safety and efficacy of adding inhaled iloprost to idiopathic PAH (IPAH) patients already receiving bosentan therapy (Clinical Trials ID: NCT00120380).
AFFILIATIONS

*Hannover Medical School, Hannover,

${ }^{\#}$ Klinikum Grosshadern, Munich,

"University of Dresden, Dresden,

+University of the Saarland,

Homburg,

sUniversity of Heidelberg,

Heidelberg,

fUniversity of Leipzig, Leipzig,

${ }^{* *}$ University of Regensburg,

Regensburg,

\#\#University of Freiburg, Freiburg, and

"Dept of Medicine, University

Hospital Eppendorf, Hamburg, Germany.

CORRESPONDENCE

M.M. Hoeper

Hannover Medical School

Dept of Respiratory Medicine

Carl-Neuberg-Str. 1

30625 Hannover

Germany

Fax: 495115328536

E-mail: hoeper.marius@mh-

hannover.de

Received:

May 012006

Accepted after revision:

June 222006

SUPPORT STATEMENT

The present study was an investigator-initiated trial financially supported by Schering-Germany, Berlin, Germany.

European Respiratory Journal Print ISSN 0903-1936 Online ISSN 1399-3003 


\section{METHODS}

\section{Study design and patient selection}

The study was designed as a 12-week, phase IV, open, randomised, controlled multicentre study in Germany. Enrolment was restricted to patients with IPAH according to the current criteria [12] in functional class III, since inhaled iloprost has been approved only for this patient population in Europe. Inclusion criteria were as follows: 1) aged 18-75 yrs; 2) bosentan therapy for $>3$ months; 3) stable functional class III for $>3$ months; 4) 6-min walk distance (6MWD) between 150 and $425 \mathrm{~m}$; and 5) serum aminotransferase levels two times below the upper level of normal.

Exclusion criteria included any other form of pulmonary hypertension, severe lung disease (total lung capacity $<70 \%$ predicted, forced expiratory volume in one second $<50 \%$ pred), clinical instability as defined by right-heart failure within the last 3 months, a $6 \mathrm{MWD}<150 \mathrm{~m}$, or a systolic blood pressure $<85 \mathrm{mmHg}$, serious accompanying diseases, concomitant sildenafil therapy, or treatment with prostanoids within 3 months prior to study entry.

Randomisation was performed by using pre-prepared, sealed envelopes, which were distributed to the centres during initiation of the study.

All measurements at week 12 were performed between $1 \mathrm{~h}$ and $3 \mathrm{~h}$ after the last inhalation of iloprost. The primary study endpoint was the change in 6MWD after 12 weeks. Secondary endpoints included changes in functional class, peak oxygen uptake, peak systolic blood pressure during exercise, and ventilatory efficacy (minute ventilation/carbon dioxide production at the anaerobic threshold) assessed during cardiopulmonary exercise testing, quality of life assessed by the 0-100 scale from the EuroQoL questionnaire [13], and clinical worsening defined as the occurrence of death, hospital admission for right-heart failure, deterioration in functional class or a decrease in $6 \mathrm{MWD}$ by $20 \%$ from baseline or $<150 \mathrm{~m}$.

Safety was assessed by documentation of adverse events and laboratory measurements including blood counts and blood chemicals at week 6 and week 12 .

Patients were seen at their centres at week 6 for a safety check and to ensure proper inhalation technique.

The study was approved by the ethics committees of all participating centres and local authorities, and all patients gave written informed consent.

\section{Treatments}

Bosentan was used at the recommended dose of $125 \mathrm{mg}$ b.i.d. Inhaled iloprost was administered six times daily at a dose of $5 \mu \mathrm{g}$ per inhalation using the Ventaneb ${ }^{\circledR}$ nebuliser (Nebutec, Elsenfeld, Germany) with treatment interruptions during the night-time. Patients assigned to the control group were not given placebo inhalations.

\section{Statistical analysis}

A sample size of 36 patients in each group was calculated to detect, with $80 \%$ power, a mean difference in the change of the $6 \mathrm{MWD}$ of $45 \mathrm{~m}$ with equal standard deviations of $75 \mathrm{~m}$ using the Mann-Whitney U-test. This change of 6MWD was derived from the results of the pivotal study with iloprost monotherapy. An interim analysis was planned a priori after enrolment of 36 patients; however, there was no predefined $\mathrm{p}$ value for premature termination.

The intention-to-treat strategy was used for all analyses including a last-observation-carried-forward strategy if data were available after 6 weeks, but not after 12 weeks. All data are expressed as mean $\pm \mathrm{SD}$ unless indicated otherwise. Statistical comparisons between groups at baseline were performed with an unpaired t-test. Analysis of within-group changes used the Wilcoxon signed-rank test, and betweengroup changes were analysed with the Mann-Whitney U-test. A p-value $<0.05$ was considered statistically significant.

\section{RESULTS}

Enrolment started in September 2004 and was stopped in December 2005 after an interim analysis of the first 36 patients revealed a low likelihood of reaching the primary end-point. At that time 40 patients were enrolled. All patients finished the study and were eligible for analysis. No patients died, and there were no episodes of hospital admission for right-heart failure. In total, 21 patients were randomised into the control group and 19 into the iloprost group; all patients were in functional class III at baseline. The duration of bosentan treatment was $16 \pm 10$ months in the control group and $20 \pm 9$ months in the iloprost group. The baseline characteristics of the patients are shown in table 1 .

\section{Study end-points}

In the control group, the 6MWD was $296 \pm 79 \mathrm{~m}$ at baseline and $297 \pm 94 \mathrm{~m}$ after 12 weeks (mean change $1 \pm 27 \mathrm{~m}$; $\mathrm{p}=0.84$ ). In the iloprost groups, the 6MWD was $317 \pm 74 \mathrm{~m}$ at baseline and $309 \pm 124 \mathrm{~m}$ after 12 weeks (mean change $-9 \pm 100 \mathrm{~m}$;

\begin{tabular}{|c|c|c|c|}
\hline & Control group & Iloprost group & p-value \\
\hline Subjects $\mathrm{n}$ & 21 & 19 & ND \\
\hline Female/male & $16 / 5$ & $15 / 4$ & ND \\
\hline Age yrs & $56 \pm 13$ & $48 \pm 14$ & 0.075 \\
\hline 6MWD m & $296 \pm 79$ & $317 \pm 74$ & 0.38 \\
\hline RAP $\mathrm{mmHg}$ & $9 \pm 5$ & $9 \pm 6$ & 0.81 \\
\hline mPAP $\mathrm{mmHg}$ & $59 \pm 19$ & $54 \pm 12$ & 0.40 \\
\hline $\mathrm{CO} L \cdot \mathrm{min}^{-1}$ & $4.1 \pm 1.2$ & $4.0 \pm 1.5$ & 0.74 \\
\hline CI L. $\min ^{-1} \cdot \mathrm{m}^{-2}$ & $2.1 \pm 0.5$ & $2.1 \pm 0.7$ & 0.80 \\
\hline PVR Wood units & $12.9 \pm 6.7$ & $13.5 \pm 6.6$ & 0.77 \\
\hline Sv, $\mathrm{O}_{2} \%$ & $63 \pm 7$ & $61 \pm 11$ & 0.62 \\
\hline 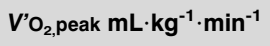 & $10.7 \pm 2.3$ & $11.8 \pm 2.5$ & 0.28 \\
\hline$V^{\prime} \mathrm{E} / \mathrm{V}^{\prime} \mathrm{CO}_{2}$ at AT & $49 \pm 7$ & $55 \pm 12$ & 0.18 \\
\hline Peak SBP mmHg & $155 \pm 19$ & $144 \pm 28$ & 0.33 \\
\hline QoL & $48 \pm 16$ & $40 \pm 17$ & 0.16 \\
\hline \multicolumn{4}{|c|}{$\begin{array}{l}\text { Data are presented as mean } \pm \mathrm{SD} \text {, unless otherwise stated. } 6 \mathrm{MWD} \text { : } 6 \text {-min } \\
\text { walking distance; } \mathrm{RAP} \text { : right atrial pressure; mPAP: mean pulmonary arterial } \\
\text { pressure; } \mathrm{CO} \text { : cardiac output; } \mathrm{Cl} \text { : cardiac index; PVR: pulmonary vascular } \\
\text { resistance; } \mathrm{Sv}, \mathrm{O}_{2} \text { : mixed venous oxygen saturation; } \mathrm{V}^{\prime} \mathrm{O}_{2} \text { peak: peak oxygen } \\
\text { uptake; } \mathrm{V}^{\prime} \mathrm{E} / \mathrm{V}^{\prime} \mathrm{CO}_{2} \text { at } \mathrm{AT} \text { : ventilation/carbon dioxide production at the anaerobic } \\
\text { threshold; peak } \mathrm{SBP} \text { : peak systolic blood pressure; QoL: quality of life score; } \\
\mathrm{ND} \text { : not done. } 1 \mathrm{mmHg}=0.133 \mathrm{kPa} \text {. }\end{array}$} \\
\hline
\end{tabular}


$\mathrm{p}=0.65$ ). Thus, the placebo-corrected difference in the 6MWD was $-10 \mathrm{~m}$ in favour of the control group $(\mathrm{p}=0.49)$.

The outcome of the trial was affected by three patients, all randomised to receive iloprost, who had clinical worsening accompanied by marked deteriorations in their 6MWD from $198 \mathrm{~m}$ to $66 \mathrm{~m}(-132 \mathrm{~m}), 264 \mathrm{~m}$ to $66 \mathrm{~m}(-198 \mathrm{~m})$, and $425 \mathrm{~m}$ to $158 \mathrm{~m}(-267 \mathrm{~m})$, respectively. In fact, more patients improved in the iloprost group than in the control group, and the median changes in $6 \mathrm{MWDs}$ were $+5 \mathrm{~m}$ in the control group and $+25 \mathrm{~m}$ in the iloprost group (fig. 1).

As shown in table 2, there were no significant differences in any of the secondary end-points. Clinical worsening (in all cases due to a decline in $6 \mathrm{MWD}$ by $>20 \%$ from baseline or to $<150 \mathrm{~m}$, and/or a deterioration in functional class) occurred in four patients in the control group and in three patients in the iloprost group.

\section{Side-effects}

One case of pneumonia occurred in the iloprost group and one case of upper respiratory tract infection was reported in the control group. One patient stopped inhaling iloprost after 6 weeks due to intractable coughing. Further side-effects reported in the iloprost group were diarrhoea $(n=2)$, headache and flushing $(n=2)$, and haemoptysis $(n=1)$; all of these events were mild in intensity.

\section{DISCUSSION}

The present trial failed to demonstrate a beneficial effect of adding inhaled iloprost to bosentan in patients with IPAH. This finding was unexpected since theoretical considerations and clinical experience provide a strong rationale for combination therapy, and previous publications have yielded promising results with the combination of bosentan and inhaled iloprost $[7,14]$. However, the present data must be interpreted with caution as the study was limited by several factors, such as the short observation period, the open-label design, and the small sample size, which did not provide sufficient power to detect a treatment benefit.

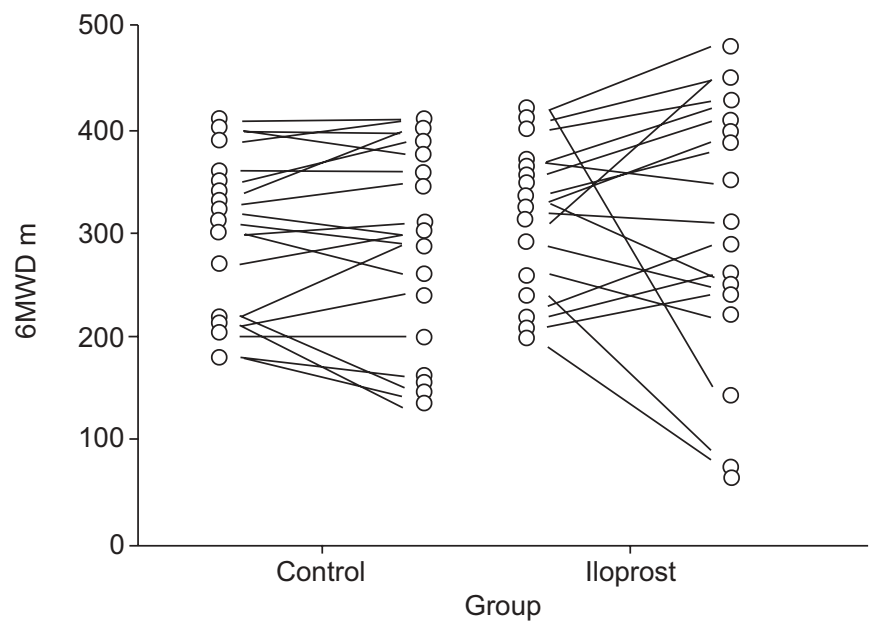

FIGURE 1. Individual changes in 6-min walking distance (6MWD) from baseline to week 12 in the control and iloprost group.

\begin{tabular}{|c|c|c|c|}
\hline & Control group & Iloprost group & p-value \\
\hline NYHA class & $+0.1 \pm 0.3$ & $-0.1 \pm 0.2$ & 0.64 \\
\hline$V^{\prime} \mathrm{O}_{2, \text { peak }}$ & $0 \pm 2$ & $-1 \pm 2$ & 0.14 \\
\hline$V^{\prime} \mathrm{E} / V^{\prime} \mathrm{CO}_{2}$ at $\mathrm{AT}$ & $+1 \pm 8$ & $-1 \pm 5$ & 0.65 \\
\hline Peak SAP & $-6 \pm 15$ & $-3 \pm 22$ & 0.45 \\
\hline QoL & $-3 \pm 11$ & $+7 \pm 19$ & 0.14 \\
\hline Clinical worsening $n$ & 4 & 3 & ND \\
\hline
\end{tabular}

Data are presented as mean $\pm \mathrm{SD}$, unless otherwise stated. NYHA: New York Heart Association; $V^{\prime} \mathrm{O}_{2}$, peak: peak oxygen uptake; $V^{\prime} E / V^{\prime} \mathrm{CO}_{2}$ at $\mathrm{AT}$ : ventilatory efficacy; SAP: systolic arterial pressure; QoL: quality of life; ND: not done.

Another study has recently assessed the safety and efficacy of adding inhaled iloprost to bosentan. The STEP trial (iloprost inhalation solution, safety and pilot efficacy trial in combination with bosentan for evaluation in pulmonary arterial hypertension) was a randomised, double-blind, placebo-controlled trial that studied the effects of 12-week treatment with inhaled iloprost in 65 patients with $\mathrm{PAH}$ already being treated with bosentan (V.V. McLaughlin, Dept of Internal Medicine, University of Michigan, Ann Arbor, MI, USA; unpublished data). In this trial, the change in 6MWD from baseline was $+4 \mathrm{~m}$ in the control group and $+30 \mathrm{~m}$ in the iloprost group, resulting in a placebo-adjusted difference of $+26 \mathrm{~m}$ in favour of the iloprost group $(\mathrm{p}=0.051)$. When interpreting these results it should be noted that the 12-week results were obtained almost immediately after inhalation of iloprost or placebo, respectively. In contrast, the pre-inhalation results at week 12 did not differ significantly in both groups (placebo-adjusted difference $19 \mathrm{~m} ; \mathrm{p}=0.14$ ). Thus, with regards to $6 \mathrm{MWD}$, the results of both the STEP study and the COMBI study may not be as different as they seem on first glance. However, in contrast to the present study, the STEP trial did show significant improvements in the iloprost group in functional class and time to clinical worsening, as well as in post-inhalation, but not pre-inhalation, haemodynamics.

One potential reason for the different outcomes of the STEP trial and the COMBI study could be that the COMBI population tended to have more severe disease as indicated both by haemodynamics (mean pulmonary vascular resistance 10.2 Wood units in STEP versus 13.2 Wood units in COMBI) as well as 6MWD at baseline ( $335 \mathrm{~m}$ versus $306 \mathrm{~m}$, respectively). It is possible that inhaled iloprost is less efficacious in patients with more advanced disease; however, there is insufficient evidence to support this conclusion.

A major limitation of the current study was the small sample size $(n=40)$. The initial power calculation was based on an expected difference in change in 6MWD of $45 \mathrm{~m}$ between groups as observed in the pivotal iloprost monotherapy trial [3]. The present results and preliminary data from other studies suggest that a difference of $25 \mathrm{~m}$ would have been more realistic and with that figure, as such, a sample size of 182 patients would have been required to reach statistical significance. With 21 patients in the control group and 19 patients in the iloprost group, the present study was affected 
out of proportion by outliers, i.e. the three patients who experienced marked clinical deterioration, who had all been randomised into the iloprost group. In addition, the present study is further limited by the fact that it was not blinded, although it would have been expected that lack of blinding would favour the iloprost group.

The present study concept of adding another drug to patients who respond insufficiently to monotherapy is only one possible approach to combination therapy for PAH. However, this approach will always favour the selection of patients who may have more resistant disease, thereby potentially underestimating the potential of combination therapy. An alternative way to address combination therapy would be the initiation of multiple therapies at the time of the diagnosis, which may yield better clinical results. This point needs to be addressed in future studies.

In conclusion, with the currently available data based on the current study and the STEP trial, it should not be concluded that the addition of inhaled iloprost to patients on bosentan treatment is more or less efficacious compared with treatment with either drug alone. The most important limitation of both studies is the short observation period of only 12 weeks. Now that effective treatments for pulmonary arterial hypertension are available, one reason to use combination therapy is further improvement in exercise tolerance but the ultimate rationale for combination therapy is better long-term outcome. Improvements in 6-min walk distance between $20 \mathrm{~m}$ and $30 \mathrm{~m}$ may be statistically significant when the sample size is large enough, but may not be truly meaningful from the perspective of both patients and physicians. The present authors hope that larger long-term studies with appropriate end-points will answer these questions.

\section{REFERENCES}

1 Rubin LJ, Badesch DB, Barst RJ, et al. Bosentan therapy for pulmonary arterial hypertension. N Engl J Med 2002; 346: 896-903.

2 Galie N, Ghofrani HA, Torbicki A, et al. Sildenafil citrate therapy for pulmonary arterial hypertension. $N$ Engl J Med 2005; 353: 2148-2157.
3 Olschewski H, Simonneau G, Galie N, et al. Inhaled iloprost for severe pulmonary hypertension. $N$ Engl J Med 2002; 347: 322-329.

4 Opitz CF, Wensel R, Winkler J, et al. Clinical efficacy and survival with first-line inhaled iloprost therapy in patients with idiopathic pulmonary arterial hypertension. Eur Heart J 2005; 26: 1895-1902.

5 Provencher S, Sitbon O, Humbert M, Cabrol S, Jais X, Simonneau G. Long-term outcome with first-line bosentan therapy in idiopathic pulmonary arterial hypertension. Eur Heart J 2006; 27: 589-595.

6 Ghofrani HA, Rose F, Schermuly RT, et al. Oral sildenafil as long-term adjunct therapy to inhaled iloprost in severe pulmonary arterial hypertension. J Am Coll Cardiol 2003; 42: 158-164.

7 Hoeper MM, Taha N, Bekjarova A, Gatzke R, Spiekerkoetter E. Bosentan treatment in patients with primary pulmonary hypertension receiving nonparenteral prostanoids. Eur Respir J 2003; 22: 330-334.

8 Hoeper MM, Faulenbach C, Golpon H, Winkler J, Welte T, Niedermeyer J. Combination therapy with bosentan and sildenafil in idiopathic pulmonary arterial hypertension. Eur Respir J 2004; 24: 1007-1010.

9 Gomberg-Maitland M, McLaughlin V, Gulati M, Rich S. Efficacy and safety of sildenafil added to treprostinil in pulmonary hypertension. Am J Cardiol 2005; 96: 1334-1336.

10 Hoeper MM, Markevych I, Spiekerkoetter E, Welte T, Niedermeyer J. Goal-oriented treatment and combination therapy for pulmonary arterial hypertension. Eur Respir J 2005; 26: 858-863.

11 Hoeper MM, Dinh-Xuan AT. Combination therapy for pulmonary arterial hypertension: still more questions than answers. Eur Respir J 2004; 24: 339-340.

12 Simonneau G, Galie N, Rubin LJ, et al. Clinical classification of pulmonary hypertension. J Am Coll Cardiol 2004; 43: Suppl. 12, 5S-12S.

13 EuroQol Group, EuroQol: a new facility for the measurement of health-related quality of life. Health Policy 1990; 16: 199-208.

14 Seyfarth HJ, Pankau H, Hammerschmidt S, Schauer J, Wirtz H, Winkler J. Bosentan improves exercise tolerance and Tei index in patients with pulmonary hypertension and prostanoid therapy. Chest 2005; 128: 709-713. 